\title{
El lado ignorado del ahorro en México
}

Conde Bonfil, Carola (2001), ¿̇Depósitos o puerquitos? Las decisiones de ahorro en México, El Colegio Mexiquense, A. C., La Colmena Milenaria, Zinacantepec, MéXico, 303 PP., ISBN 970-669-036-0

"Hablar de ahorro familiar en tiempos de crisis parece ser, en primera instancia, no sólo ilógico, sino también inapropiado. La pérdida constante de poder adquisitivo de los salarios, el cierre frecuente de fuentes de trabajo y el consecuente aumento del desempleo, el aumento del número de mexicanos que viven en pobreza extrema, la continua presencia de expectativas inflacionarias y devaluatorias, etc., son sólo algunos de los elementos que pueden fácilmente mencionarse para resaltar las dificultades que enfrentan las familias para considerar el ahorro en sus decisiones respecto al ingreso disponible".

Este es el inicio de un libro provocador que trata de atraer la atención hacia un tema olvidado, relegado no sólo por la literatura económica, sino también por los diseñadores de las políticas financieras mexicanas y de otros países, y, principalmente por las mismas instituciones financieras: el ahorro de los pobres.

Es interesante observar que, pese a la importancia atribuida en la literatura económica del financiamiento del crecimiento, la reforma del sistema financiero mexicano no ha atraído la atención de los actores políticos, como sí lo han hecho otras reformas. Aun cuando no se ha logrado el consenso sobre qué tipo de reformas llevar a cabo, existe acuerdo en que hacen falta cambios profundos en los temas fiscal, laboral y energético, por citar algunos ejemplos. Sin embargo, curiosamente, a pesar de la evidente concentración del mercado, los elevados diferenciales de tasas de interés y la escasez de crédito a los sectores productivos, no ocupa un lugar prioritario en el tema de las reformas, la regulación y eficiencia del sistema financiero. Éste es un tema complejo que involucra multiplicidad de aspectos del financiamiento y exige la participación de todos los agentes interesados.

El libro de Carola Conde analiza uno de los aspectos del financiamiento, no el más socorrido, por cierto, el tema del ahorro de los pobres. Por lo tanto, un libro como éste tenía que ser dirigido no sólo al mundo académico, sino también a los responsables de 
definir las políticas financieras dentro del sector gubernamental, a las instituciones financieras mismas que, en teoría, constituyen los intermediarios financieros en el sentido de canalizar los ahorros hacia los sectores que requieren de financiamiento y, sobre todo, al público en general que es además el actor principal de este texto.

¿Depósitos o puerquitos? es un título muy sugerente que refleja de manera creativa el objeto de análisis de este libro: analizar la disyuntiva real que enfrentan los ahorradores, particularmente de los ahorradores pobres, entre canalizar sus ahorros hacia formas monetarias o en especie o, más aún, canalizar sus ahorros hacia las instituciones financieras formales o hacia opciones informales. Como demuestra la autora, la disyuntiva se ha resuelto dentro de este segmento de la población en favor de los puerquitos, es decir de las opciones informales (fuera del sistema financiero) para ahorrar, porque, concluye, los pobres sí ahorran, que es otro de los aspectos que se trata de destacar.

Para abordar el tema de las decisiones de ahorro en México, como reza el subtítulo del libro, Carola Conde presenta un texto integrado por 303 páginas, acompañado de un disco con los anexos metodológicos y 54 cuadros estadísticos. Consta de nueve capítulos agrupados en tres partes.

En la primera parte se lleva a cabo una revisión crítica de las teorías y los conceptos del ahorro, así como una amplia exposición del estado del arte de la investigación sobre el ahorro y su relación con otras variables macroeconómicas (inversión, crecimiento, tasas de interés, etc.).

Un tema medular en la construcción de este libro es la definición más completa del ahorro que ofrece Carola Conde. Esta definición se aleja de la tesis macroeconómica convencional de ahorro, es decir, lo que queda después de restar el consumo al ingreso disponible. La definición que ofrece involucra una connotación inter-temporal del consumo, en el sentido de que el ahorro presente puede verse como la posposición del consumo hacia periodos posteriores, lo cual da mejor cuenta de la conducta de los consumidores. Pero la definición va más allá para incorporar aspectos poco comunes. Específicamente, considera lo siguiente:

“[...] el ahorro familiar debe ser conceptuado como el conjunto de decisiones que toman premeditadamente los integrantes de un hogar para: 1) homogeneizar su consumo a lo largo del tiempo (ante percepciones irregulares en montos y plazos); 2) asegurar la disponibilidad de un 
cierto ingreso (y, por tanto, un determinado nivel de vida) en un momento posterior, o 3 ) incrementar su riqueza (incluyendo el acervo de bienes y la formación de capital humano) y su bienestar futuro".

Esta formulación tiene dos implicaciones. Primero, por estar basada en una idea microeconómica, permite incluir (y especialmente medir) el ahorro fuera del sistema financiero y en especie, lo cual es muy común entre la gente de bajos recursos de este país. Segundo, esta definición que incluye componentes hasta ahora ignorados, abre la posibilidad de captación del ahorro mediante la creación de instrumentos (e instituciones) apropiadas. Una amplia revisión de las modalidades de este tipo de ahorro se presenta también en esta parte.

En la segunda parte se realiza un análisis del ahorro en México para el periodo 1968 - 1995. Sobre la base del concepto de ahorro mencionado, se valida la hipótesis central: sí existe capacidad de ahorro en los grupos sociales de menores ingresos en México. Más aún, los datos presentados por Carola Conde muestran que el segmento del ahorro de los pobres estudiado no sólo es cuantitativamente superior al ahorro interno, sino al ahorro total de la economía. Y este es un punto de fundamental importancia en la literatura sobre el ahorro en México, porque abre la posibilidad de encontrar fuentes alternativas para el financiamiento al desarrollo. En particular, esto lanza dudas sobre la pertinencia del tipo de política económica instaurada en el país con respecto a la promoción desmedida de México en el exterior. Estos resultados cuestionan la transformación de la inversión extranjera directa en protagonista del desarrollo. Sin duda que ésta es importante, pero la existencia de fuentes de financiamiento internas nos harían sin duda menos vulnerables y menos dependientes de los vaivenes de la ahora más inestable economía internacional.

Y si existe, ¿̇por qué ese ahorro no se ha canalizado hacia los sectores productivos? La respuesta que Carola Conde ofrece -mediante el análisis mensual de la captación por tipo de instrumento durante 28 años- es que el sistema financiero ha discriminado (y todavía lo hace) a los pequeños ahorradores, al no crear instrumentos adecuados para la captación de su ahorro y al otorgar tasas de interés reales negativas a los pocos ahorradores, lo cual representa pérdidas en su patrimonio.

Como consecuencia, las familias de menores recursos ahorran principalmente fuera del sistema financiero, ya sea en mecanismos e instituciones monetarias informales o en especie (ahorro 
no monetario). Se demuestra que incluso hogares ubicados en los deciles con más bajos ingresos de la Encuesta Nacional de Ingreso-Gasto de los Hogares del Instituto Nacional de Estadística Geografía e Informática pueden llevar a cabo ciertos tipos de ahorro no monetario o monetario informal. Este es un hallazgo importante y quizá un tanto sorprendente, dado que los estudios de pobreza sugieren que 60 o 40 millones de personas de este país viven en condiciones de pobreza o pobreza extrema. Si esto es así, obviamente la conclusión natural es pensar que los pobres no ahorran. Pero este planteamiento olvida algo básico: la capacidad de estos grupos de población para desarrollar estrategias de sobrevivencia, y de hecho, como lo muestra este libro, de estrategias alternativas de ahorro. Por tanto, aunque sorprendente, este resultado no debería serlo tanto.

La tercera parte se concentra en el estudio de la posibilidad de captar el ahorro de las familias de menores ingresos. Para ello se revisan experiencias internacionales y nacionales, evaluando las enseñanzas de las experiencias estudiadas. Las características común de estos experimentos es que están dirigidos a gente pobre o en situación de pobreza extrema.

En resumen, dado que los pobres sí ahorran, la autora subraya la necesidad de crear instrumentos e instituciones financieras adecuadas para captar el ahorro de los pobres, no sólo para mejorar su bienestar, sino para que las instituciones financieras cumplan realmente su función de intermediación.

En mi opinión, algunos aspectos básicos por analizar para lograr una transformación incluyente del sistema financiero son los siguientes: ¿Cuál puede ser el interés de las instituciones financieras para atraer los ahorros de los pobres y ceder créditos diferentes a los que otorgan al gobierno o al consumo privado? Su posición en estos rubros es bastante ventajosa y cómoda. Este aspecto nos lleva al corazón mismo de uno de los principales obstáculos al crecimiento sostenido de largo plazo: la débil influencia de las instituciones financieras en el financiamiento del desarrollo por necesidad de retomarlas.

Una mayor competencia entre ellas (es decir, una menor concentración del mercado) contribuiría sin duda a que mejoraran las opciones de ahorro y las condiciones del crédito. ¿Cómo hacerlo? ¿Cómo modificar los patrones de conducta de los pobres en el tema del ahorro? ¿Cómo convencerlos de que el ahorro formal puede ser ventajoso para ellos después de la experiencia 
con las UDI a la quiebra 'aparente' de las cajas de ahorro, por ejemplo? El libro ¿Depósitos o puerquitos? Las decisiones de ahorro en México plantea una serie de interrogantes que demandan una respuesta pronta, si se quieren sentar las bases para el crecimiento sostenible de la economía mexicana. La agenda de investigación pendiente por abordar es por demás interesante. En este contexto, el libro constituye un avance importante en el análisis de la pobreza, del ahorro y del financiamiento para el desarrollo. No cabe la menor duda de que es una lectura obligada para los interesados en el tema financiero.

\author{
Pablo Mejía \\ pmejia@cmq.edu.mx
}


